Chronic Obstructive Pulmonary Diseases: Journal of the COPD Foundation

\author{
Original Research
}

\title{
GOLD Stage and Treatment in COPD: A 500 Patient Point Prevalence Study
}

\author{
Katherine A. Safka, MD, FRCP(C) ${ }^{1}$ Joshua Wald, MD, FRCP(C $)^{1}$ Hongyu Wang, MD, PhD ${ }^{1}$ Luke McIvor $^{1}$ \\ Andrew McIvor, MD, MSc, $\operatorname{FRCP}(C)^{1}$
}

\begin{abstract}
Background and Objective: The Global initiative for chronic Obstructive Lung Disease (GOLD) guidelines recommend using a combination of spirometry, symptoms and exacerbation history to classify patients into 4 categories (A, B, C, D) to guide treatment decisions along with a stepwise increase in therapy. Our objectives were to identify the GOLD stage of patients in respiratory outpatient clinics and assess how treatment compares to guideline recommendations.

Methods: This was a point prevalence study using a convenience sample of 500 patients with chronic obstructive pulmonary disease (COPD) from a single tertiary care outpatient respiratory clinic.

Results: Patients' GOLD classification was determined based on symptoms (modified Medical Research Council [mMRC] dyspnea scale, COPD Assessment Test [CAT]), spirometry and self-reported exacerbation history. A total of $8.2 \%$ of patients were in the GOLD group $A, 28.3 \%$ in group B, $4.2 \%$ in group $C$ and $59.2 \%$ in group D.

Conclusions: In this 500 patient point prevalence study we report a low proportion of patients in GOLD group $C$ and a high level of inhaled corticosteroids (ICS)/ long-acting beta2-agonist (LABA) and triple therapy use throughout all GOLD categories.

Clinical Implications: The GOLD guidelines have attempted to provide direction to practitioners by grouping patients into 4 groups based on symptoms and exacerbations however, the low prevalence of GOLD group C may indicate that not all of these groupings are clinically relevant. Future research is needed to better identify clinically relevant phenotypes that predict benefit from ICS and methods to promote guideline concordant management in COPD.
\end{abstract}

\begin{abstract}
Abbreviations: Global initiative for obstructive Lung Disease, GOLD; chronic obstructive pulmonary disease, COPD; modified Medical Research Council, mMRC; COPD Assessment Test, CAT; inhaled corticosteroid, ICS; long-acting beta2-agonist, LABA; forced expiratory volume in 1 second, $\mathbf{F E V}_{\mathbf{1}}$; forced vital capacity, FVC; standard deviation, SD; long-acting muscarinic antagonist, LAMA; short-acting beta2agonist, SABA; short-acting muscarinic antagonist, SAMA; phosphodiesterase-4, PDE4

Funding Support: Financial support provided by Novartis Pharmaceuticals Canada, Inc

Date of Acceptance: October 19, 2016

Citation: Safka KA, Wald J, Wang H, McIvor L, McIvor A. GOLD stage and treatment in COPD: A 500 patient point prevalence study. Chronic Obstr Pulm Dis. 2017;4(1):45-55. doi: https://doi.org/10.15326/jcopdf.4.1.2016.0126
\end{abstract}

1 Firestone Institute for Respiratory Health, McMaster University, Hamilton, Ontario, Canada

\section{Keywords:}

Global initiative for obstructive Lung Disease; GOLD; inhaled corticosteroids; long-acting beta2-agonist; short-acting beta2agonist

\section{Address correspondence to:}

R.A. McIvor, MD

T2127 FIRH, St. Joseph's Healthcare

50 Charlton Avenue East

McMaster University

Hamilton, Ontario, Canada

Email: amcivor@stjosham.on.ca

Phone: (905)522-1155 Ext 34330 


\section{Introduction}

Chronic obstructive pulmonary disease (COPD) is the most common lung disease in the world ${ }^{1}$ and is characterized by incomplete reversible airflow limitation and is often associated with a smoking history and increasing age. ${ }^{2}$ The Canadian guidelines on COPD have not been updated since 2008. At the present time, the Global initiative for Obstructive Lung Disease (GOLD) guidelines ${ }^{3}$ for COPD management have been widely adopted and endorsed. For the first time, the GOLD guidelines specifically identify COPD phenotypes and separate patients into risk stratification categories A, B, C, D suggesting a preferred treatment regimen related to their classification. (Figure 1)

Previously, the severity of COPD was based solely on forced expiratory volume in 1 second $\left(F E V_{1}\right)$, a marker of airflow limitation. FEV 1 is a poor marker of disease status. It is based on an artificial maneuver and does not always correlate with clinically relevant outcomes such as dyspnea, health status, exercise capacity and exacerbations. Patients with a similar FEV 1 may present with different phenotypes. ${ }^{4}$ Therefore, in 2011, the GOLD Strategy developed the combined COPD assessment, which categorizes patients based on airflow limitation ( $\mathrm{FEV}_{1}$ ), symptoms (using modified Medical Resource Council [mMRC] dyspnea scale or COPD Assessment Test [CAT] score) as well as exacerbation history. This phenotypic categorization is felt to better reflect the complexity of COPD rather than the $F E V_{1}$ Figure 1. GOLD Strategy for COPD Categorization alone. Likewise, in the past, COPD treatment recommendations were based solely on spirometry. The current treatmentrecommendations proposed by the GOLD Strategy suggest a treatment regimen for the various COPD phenotypes, taking into account the complexity of COPD. (Table 1)

COPD poses a significant economic, social and personal burden. COPD now accounts for the highest rate of hospital admissions among major chronic illnesses in Canada. ${ }^{1}$ It has been reported that admission for $\mathrm{COPD}$ exacerbations averaged a 10-day length of stay at a cost of $\$ 10,000$ per stay. ${ }^{1}$ The total cost of COPD hospitalizations is estimated at $\$ 1.5$ billion per year. ${ }^{1}$ Mittman et al states that the simplest way to reduce hospital admissions for COPD is to prevent COPD exacerbations by treating the disease appropriately. ${ }^{1}$ Given the prevalence of COPD and the burden it carries, it is clear that guideline-based treatment is of the utmost importance in minimizing the burden of this disease.

Despite the availability and promotion of evidencebased guidelines, patients around the world are often not receiving optimal care. In a study of prescribing patterns in the United Kingdom, Price et al found that over half of patients with COPD being treated in primary care were on an inhaled corticosteroid (ICS). ${ }^{5}$ In Spain, Miguel-Díez et al reported that $34.5 \%$ of patients were on ICSs of which over $18 \%$ were judged to be inappropriate, ${ }^{6}$ while in Mexico, Laniado-Laborin et al demonstrated in a pilot study that only a minority of COPD patients were receiving state-of-the-art treatment at the primary care level. ${ }^{7}$ Under treatment of COPD may contribute to more frequent exacerbations and high symptom burden while inappropriate introduction of inhaled corticosteroids would add to the cost of treatment and expose patients to side effects including an increased risk of pneumonia. We therefore proposed a point prevalence study to identify a cohort of Canadian patients being treated at a single tertiary outpatient respiratory clinic. With this information we wanted to build a profile of current GOLD stages of patients seen

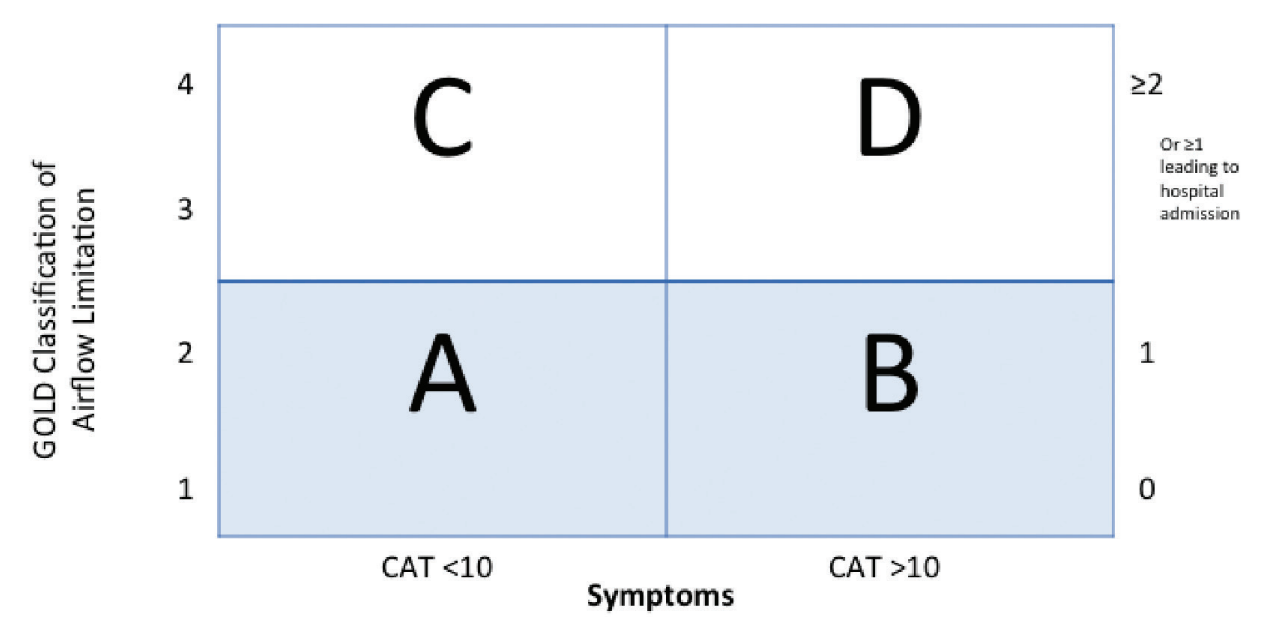

mMRC 0-1

\section{Breathlessness}

$\mathrm{mMRC} \geq 2$ 


\section{Table 1. Pharmacologic Therapy for Stable COPD as per Global Initiative for Obstructive Lung Disease $^{3}$}

\begin{tabular}{cccc}
$\begin{array}{l}\text { Patient } \\
\text { Group }\end{array}$ & $\begin{array}{c}\text { Recommended } \\
\text { First Choice }\end{array}$ & Alternative Choice & $\begin{array}{c}\text { Other Possible } \\
\text { Treatments }\end{array}$ \\
\hline
\end{tabular}

\begin{tabular}{c|c|c|c}
\hline A & $\begin{array}{c}\text { SA anticholinergic prn } \\
\text { OR }\end{array}$ & LA anticholinergic & Theophylline \\
OR & OR & \\
& & LA beta2-agonist \\
OR & \\
& SA beta2-agonist and \\
SA anticholinergic & \\
\hline B & LA anticholinergic & LA anticholinergic and & \\
OR & LA beta2-agonist & $\begin{array}{c}\text { SA beta2-agonist and/ } \\
\text { or SA anticholinergic }\end{array}$ \\
& LA beta2-agonist & &
\end{tabular}

Theophylline

\begin{tabular}{l|c|c|c|}
\hline C & ICS + LA beta2-agonist or \\
LA anticholinergic & $\begin{array}{c}\text { LA anticholinergic and } \\
\text { LA beta2-agonist } \\
\text { OR }\end{array}$ & $\begin{array}{c}\text { SA beta2-agonist and/ } \\
\text { or SA anticholinergic }\end{array}$ \\
& $\begin{array}{c}\text { LA anticholinergic and } \\
\text { PDE-4 inhibitor }\end{array}$ & Theophylline \\
& OR & \\
& LA beta2-agonist and & \\
& PDE-4 inhibitor & \\
\hline
\end{tabular}

D ICS + LA beta2-agonist and/
or LA anticholinergic

ICS + LA beta2-agonist

and LA anticholinergic OR

ICS + LA beta2-agonist and PDE-4 inhibitor OR

LA anticholinergic and LA beta2-agonist OR

LA anticholinergic and PDE-4 inhibitor

a questionnaire and to allow their spirometry results to be collected.

\section{Participants}

All participants met the following inclusion criteria: A diagnosis of COPD made by a physician, at least 40 years of age, a minimum 20 pack year smoking history and a $\mathrm{FEV}_{1} /$ forced vital capacity (FVC) ratio <0.7. All participants provided informed consent and were able to perform spirometry according to American Thoracic Society criteria. ${ }^{8}$

\section{Assessment of Symptoms}

A self-administered questionnaire was used to obtain demographic information, smoking history, current respiratory medications and vaccination status. Adherence to prescribed medication was assessed by patient self-reporting. Dyspnea was measured using the mMRC Dyspnea Scale, a validated questionnaire to assess symptoms in COPD, which grades symptoms from 0 (minimal dyspnea) to 4 (severe dyspnea with activities of daily living). ${ }^{9}$ Symptoms burden was assessed via the selfadministered CAT. The CAT is an 8-item unidimensional measure of health status impairment in COPD, which yields a score between 0-40 with higher scores indicating a

LA=long-acting; SA=short-acting; ICS=inhaled corticosteroid; $\mathrm{PDE}=$ phosphodiesterase

in the clinic and ascertain if the current treatment plans were in accordance with current guidelines.

\section{Methods}

\section{Study Design}

This was a point prevalence study approved by the research ethics boards at McMaster University. Patients who had spirometry testing performed at the Firestone Institute for Respiratory Health in Hamilton, Ontario were approached prospectively and asked to complete higher symptom burden. ${ }^{10}$ A COPD exacerbation was defined, as per GOLD, as an acute event characterized by a worsening of the patient's respiratory symptoms that is beyond normal day-to-day variations and leads to a change in medication. ${ }^{3}$ Exacerbation history was assessed by patient self-report of hospitalizations, emergency department visits, and prescriptions of corticosteroids for acute dyspnea over the last 12 months.

\section{Assessment of Lung Function}

Lung function was measured by spirometry according 
to ATS standards (NHANES III reference values). ${ }^{8}$ Patients with an $\mathrm{FEV}_{1} / \mathrm{FVC}<0.7$ and a $<200 \mathrm{cc}$ or $<12 \%$ change in $\mathrm{FEV}_{1}$ or $\mathrm{FVC}$ post bronchodilator were considered to participate in the study. The $\mathrm{FEV}_{1}$ percent predicted was recorded for staging of COPD according to GOLD Combined COPD Assessment. ${ }^{3}$

\section{Results}

\section{Patient Characteristics}

A total of 500 patients were assessed. Of these, 266 (53.4\%) were male. The mean age of participants was 68.4 years (standard deviation [SD] 9.9). The mean FEV1 was 49.0\% (SD 19.0\%). All patients had a history of smoking, with a mean pack year history of 55.4 (SD 31.8). A total of $31.9 \%$ were current smokers while 68.1\% were ex-smokers. (Table 2)

\section{GOLD Stage Classification}

Studies have consistently shown a difference in GOLD classification of some patients when different measures of symptoms are used (mMRC versus CAT). ${ }^{11,12}$ This was apparent in our population with a higher proportion of patients being classified as more symptomatic by the CAT than by the mMRC score. If the CAT score was used, there were $10.4 \%$ of patients in GOLD group A, $26 \%$ of patients in GOLD group B, $7 \%$ of patients in GOLD group $C$ and $56.2 \%$ of patients in GOLD group $D$. When the $\mathrm{mMRC}$ score was used, the distribution is as follows: $20.4 \%$ patients in GOLD group A, $15.6 \%$ of patients in GOLD group B, $15.2 \%$ of patients in GOLD group $C$ and $47.8 \%$ of patients in GOLD group D.

For the purposes of analysis we counted patients as being more symptomatic if they had either a CAT score of greater than 10 or an $\mathrm{mMRC}$ greater than or equal to 2 . This lead to a total of $8.2 \%$ of patients in GOLD group A, $28.3 \%$ in group B, $4.2 \%$ in group $C$ and $59.2 \%$ in GOLD group D. (Figure 2)

\section{Non-Pharmacologic Management}

Group A demonstrated a $68.3 \%$ flu vaccination rate and a $63.4 \%$ pneumococcal vaccination rate. Group B demonstrated a $70.7 \%$ flu vaccination and $47.9 \%$ pneumococcal vaccination rate. Group C had a $71.4 \% \mathrm{flu}$ vaccination and $57.1 \%$ pneumococcal vaccination rate and Group D demonstrated a 69.2\% flu vaccination and $62.4 \%$ pneumococcal vaccination rate. In total, $69.6 \%$ of patients were up to date with their flu vaccination and $58.1 \%$ with their pneumococcal vaccine. Smoking cessation rates among the groups were as follows: Group A 65.9\%, Group B 65.2\%, Group C 76.2\% and Group D 69.2\%. (Figure 3)

\section{Adherence}

Adherence to prescribed inhaler therapy was measured by patient self-report of frequency of missed doses. Overall adherence was adequate with $77.5 \%$ of patients reporting that they never or only "once in a while" forgot to take their inhalers. There was no significant difference in self-reported adherence with increasing severity of disease with $70.4 \%$ of patients in GOLD group A reporting never or "once in a while" forgetting inhalers compared to $76.6 \%$ for GOLD group D (Figure 4).

\section{Treatment}

Data was collected on each patient's current regular COPD inhaler regimen. A total of $70.9 \%$ of patients were on a long-acting muscarinic antagonist (LAMA), $67.1 \%$ were on an ICS/LABA combination inhaler,

\section{Table 2. Baseline Characteristics of Study Population}

\begin{tabular}{|c|c|c|c|c|c|}
\hline & A & B & C & $\mathrm{D}$ & Total \\
\hline Male (\%) & 58.5 & 51.8 & 61.9 & 52.9 & 53.4 \\
\hline Mean Age (yr) & $70.8 \pm 9.4$ & $70.0 \pm 10.3$ & $68.5 \pm 8.4$ & $67.4 \pm 9.7$ & $68.4 \pm 9.9$ \\
\hline Smoking Hx (pk/yr) & $49.8 \pm 30.5$ & $54.2 \pm 35.3$ & $51.9 \pm 28.3$ & $56.9 \pm 30.5$ & $55.4 \pm 31.8$ \\
\hline Ex-Smoker N, (\%) & $27(65.9)$ & $92(65.2)$ & $16(76.2)$ & $204(69.2)$ & $339(68.1)$ \\
\hline Current Smoker (\%) & $14(34.1)$ & $49(34.8)$ & $5(23.8)$ & $91(30.8)$ & $159(31.9)$ \\
\hline FEV $_{1}(\%)$ & $70.8 \pm 14.4$ & $65.1 \pm 11.7$ & $46.1 \pm 10.3$ & $38.5 \pm 14.4$ & $49.0 \pm 19.0$ \\
\hline CAT Score & $5.8 \pm 2.8$ & $17.0 \pm 7.1$ & $5.4 \pm 3.0$ & $21.6 \pm 7.6$ & $18.3 \pm 8.7$ \\
\hline
\end{tabular}

$\mathrm{Hx}=$ history; $\mathrm{FEV}_{1}=$ forced expiratory volume in 1 second; $\mathrm{CAT}=\mathrm{COPD}$ Assessment Test 


\section{Figure 2. GOLD Stage Classification}

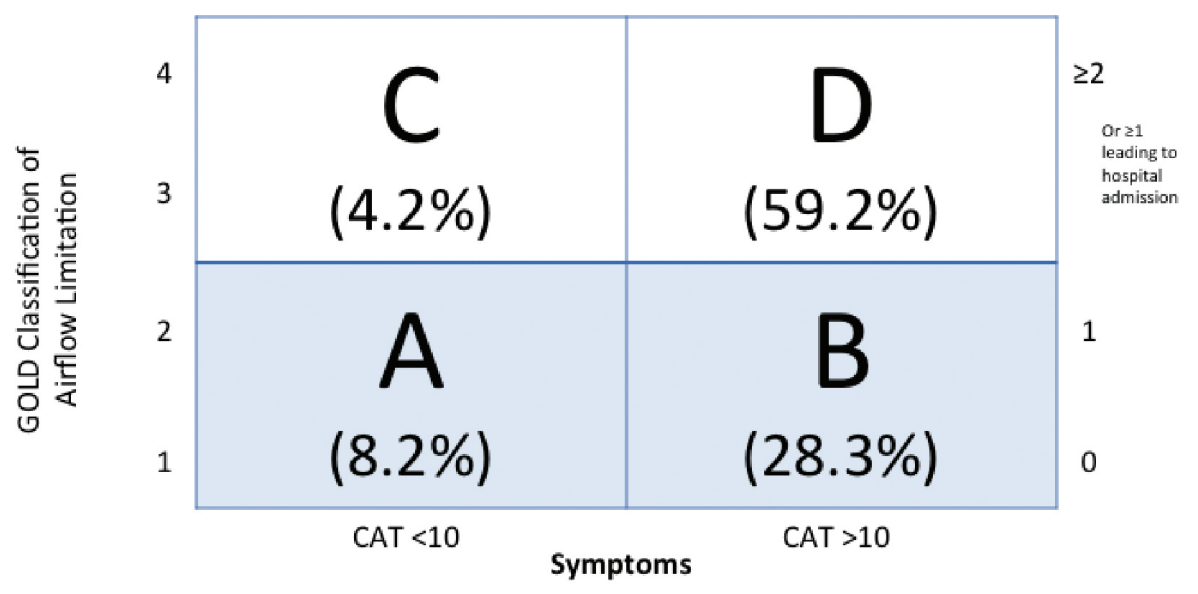

mMRC 0-1
In total, $53.6 \%$ of patients were on triple therapy. (Figure 6)

\section{Discussion}

In 2011, GOLD developed a new $\geq$ categorization for COPD patients based on a combination of $\mathrm{FEV}_{1}$, dyspnea and exacerbation history rather than $\mathrm{FEV}_{1}$ alone. Based on these categorizations an incremental step-wise treatment algorithm was proposed.

In our cohort of patients assessed from a single tertiary center respiratory clinic, we found the highest percentage of patients to be in GOLD categories B and D. This may have reflected a referral bias in that patients who are very symptomatic are more likely to be referred for specialized care. There were fewer patients in Category A, however, slightly more than expected given this cohort has mild, asymptomatic disease which is typically managed by primary care physicians. This may reflect an over-burdened primary care sector leading to increased referrals to subspecialty practice. This in turn increases the burden on subspecialty practices, leading to longer wait times and less time available for patients with more severe disease.

The lack of patients in Category C is in keeping with previous studies where category $C$ only comprised $11.3 \%$ of patients seen. ${ }^{13}$ The low percentage of patients in this
$68.3 \%$ were on a shorting-acting beta2-agonist (SABA), $11.4 \%$ were on a short-acting muscarinic antagonist (SAMA), $4.4 \%$ on a LABA without ICS and $1 \%$ were on phosphodiesterase-4 (PDE4) inhibitors. (Figure 5)

A total of $26.8 \%$ of patients in GOLD category A were on triple therapy with LAMA, ICS/LABA, 42.6\% in Group B, 57.1\% in Group C and $62.4 \%$ in Group D. category likely indicates that patients with a low FEV 1 or frequent exacerbations also typically have a higher symptom burden and rarely remain less symptomatic.

There was no significant difference in age, gender, smoking history or percentage of former smokers between the categories. There was a trend towards an increased number of pack years smoked in Group 


\section{Figure 4. Adherence to Inhaled Medication}

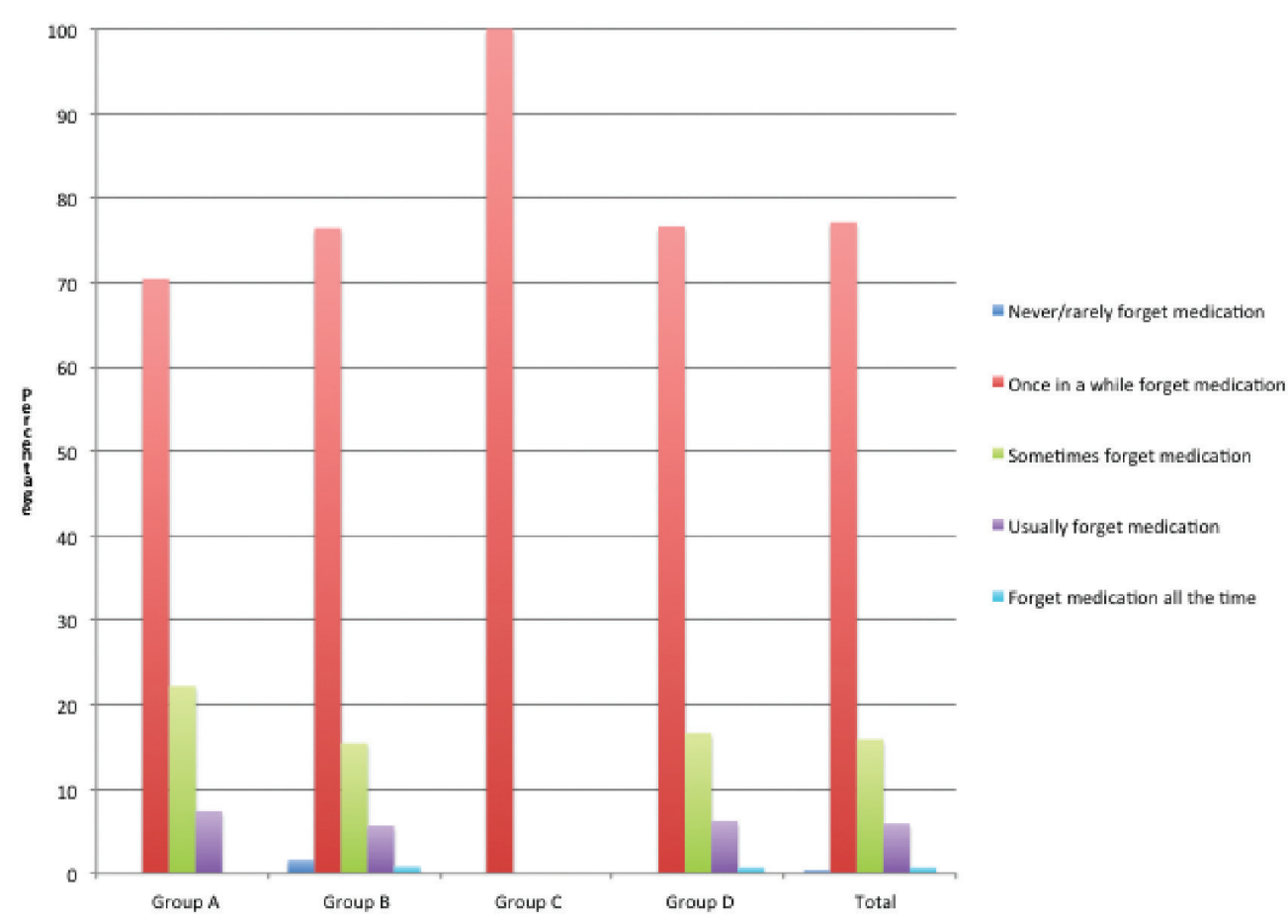

\section{Figure 5. Pharmacologic Management of Stable COPD}

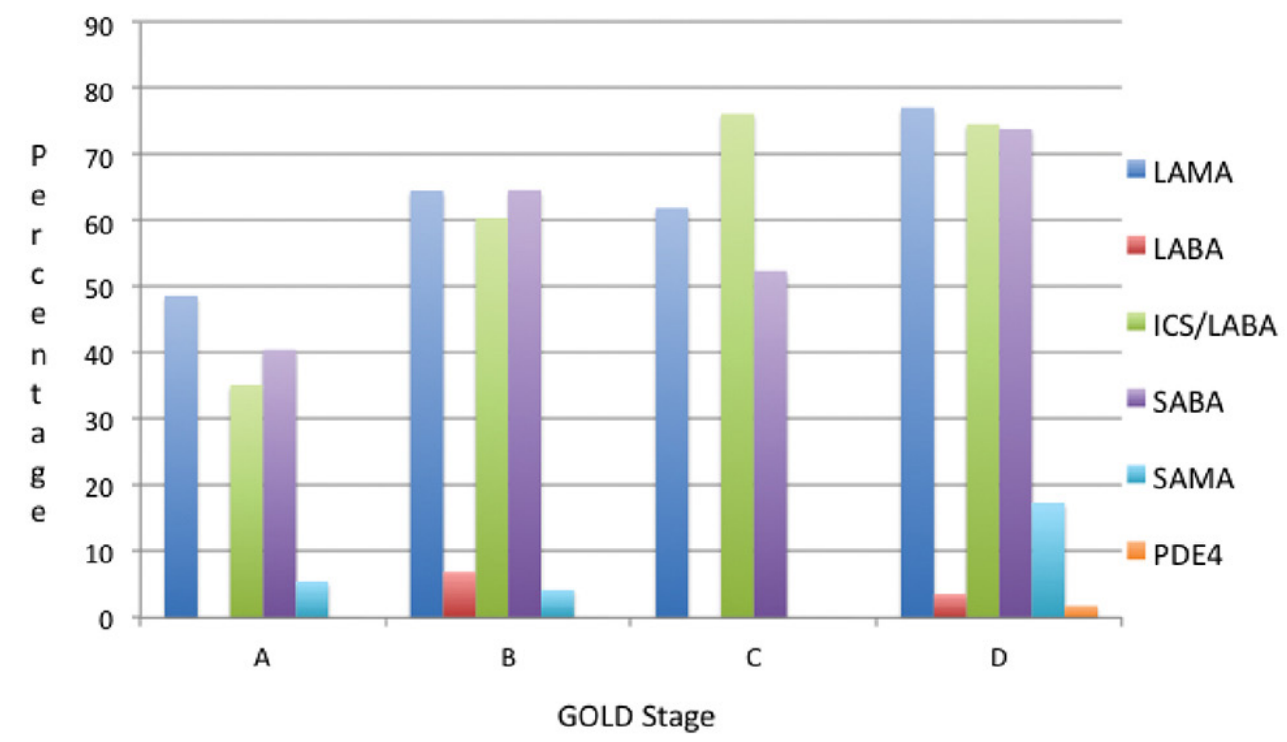

Inhaler therapy based on GOLD Stage Classification. Group A had high percentage of LAMA, ICS/LABA and SABA use. Group B had therapy consisting of predominantly LAMA,

ICS/LABA and SABA. Results were similar for Group C and D.
D, reflecting the increased disease severity in this group. In addition, the percentage of former smokers was lowest in Category B. This is a key group to target before their disease progresses and irreversible, severe lung damage has occurred. It is suggested that smoking cessation techniques be focused on all groups, but perhaps more so in this group to prevent them from developing worsening airflow obstruction or frequent admissions for exacerbations.

\section{Management}

Non-Pharmacologic Therapy:

The GOLD guidelines recommend smoking cessation, flu and pneumococcal vaccinations for patients with COPD in Groups A through D. ${ }^{3}$

Vaccinations are one way to reduce exacerbations, which are known to cause a more rapid decline in lung function, increased morbidity and mortality. It has been demonstrated that inactivated influenza vaccines in COPD patients leads to a significant reduction in the total number of exacerbations per vaccinated individual compared with those who received placebo. ${ }^{14,15}$ While the data is less robust for the pneumococcal vaccine, it is still recommended in this population. In our population of patients, there were adequate success rates with the aforementioned nonpharmacologic therapies. There was at least a $50 \%$ success rate for the above interventions.

Smoking cessation is of the utmost importance in halting 


\section{Figure 6. Triple Therapy Usage Among COPD Stages}

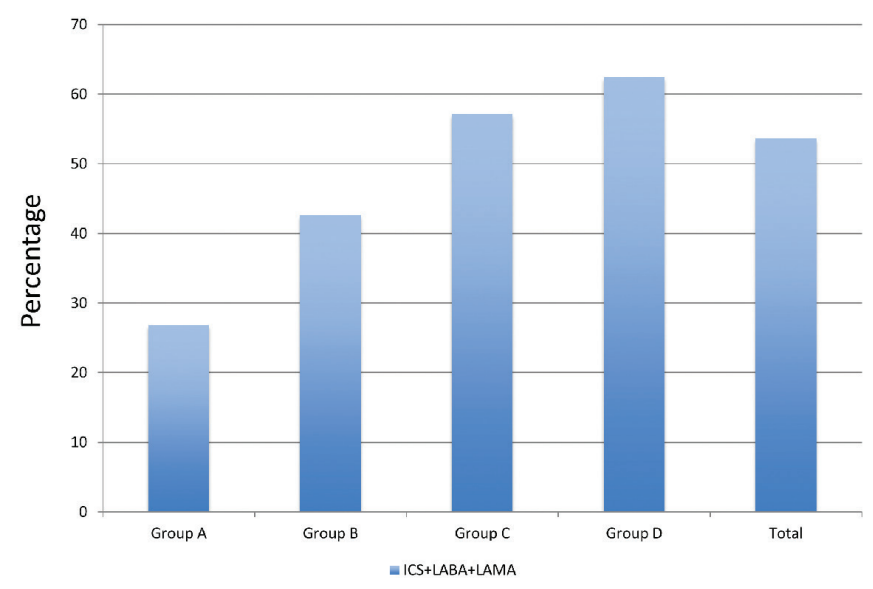

All groups demonstrate a heavy reliance on triple therapy, with highest percentages of usage in Group C and D: $57.1 \%$ of Group C on triple therapy and $62.4 \%$ of Group D relying on triple therapy.

\section{Figure 7. Proposed Simplification of Current GOLD Classification}

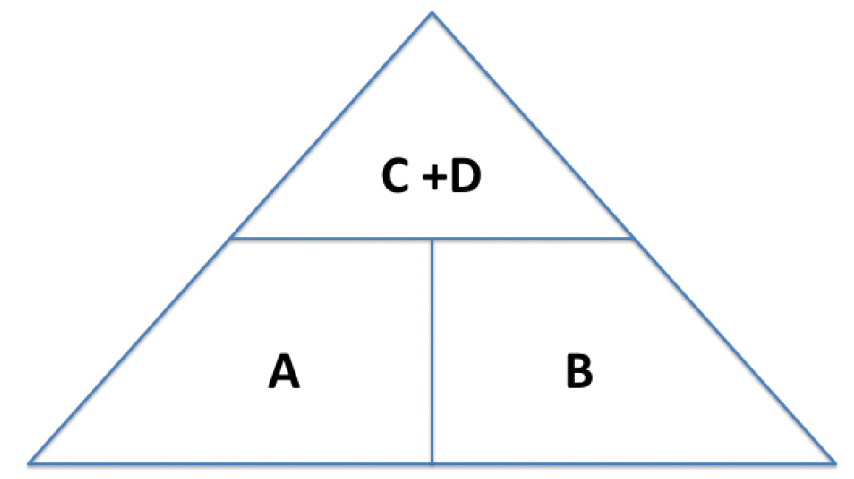

progression of lung function decline and is one intervention that has been shown to have a mortality benefit. ${ }^{16}$ As such, this should be emphasized at every visit and as early in the disease as possible. Smoking cessation rates among this sample population were above $60 \%$ in all categories. The fact that nearly $31 \%$ of patients in Group D were still smoking despite having severe, symptomatic disease means that there is still room for improvement in this domain.

Non-pharmacological management is the basis of treatment in all GOLD categories. This includes smoking cessation and vaccinations as well as encouragement of physical activity and pulmonary rehabilitation. Pulmonary rehabilitation is recommended by current guidelines for patients who remain symptomatic despite optimal bronchodilator therapy and also within 1 month following an acute exacerbation. ${ }^{17}$ Pulmonary rehabilitation has beneficial outcomes in many patient domains, such as dyspnea, exercise performance, disability and quality of life. Perhaps the most important impact of pulmonary rehabilitation is post an exacerbation where it is has been shown to decrease hospital readmission rates and death in addition to providing increased exercise tolerance and symptomatic improvement. ${ }^{18}$ This is particularly important given the data from Suissa et al which demonstrated that after the second severe COPD exacerbation, there is a rapid decline in health status and subsequent exacerbations occur at a much more rapid rate. ${ }^{19}$ Focus should be on preventing subsequent exacerbations and optimal management of exacerbations. ${ }^{19}$ Nonpharmacological therapy including vaccinations and pulmonary rehabilitation can help prevent subsequent exacerbations and the rapid decline described by Suissa et al.

\section{Pharmacological Therapy:}

Group A: In our population of Group A patients, we report an overuse of ICS/LABA and even triple therapy with ICS/LABA/LAMA. There is under usage of SABA/SAMA prn in this cohort with heavy reliance on second line therapy or therapy that is not concordant with current guideline recommendations. Given the small potential benefit in this population they are more likely to experience a net harm related to side effects from excessive inhaler therapy.

Group B: In our population of Group B patients, there is heavy reliance on dual ICS/LABA combination therapy or triple therapy with LAMA/LABA/ICS. ICS therapy is not recommended in this group and is over-prescribed in this population.

Group C: This group has few symptoms, but is at high risk of exacerbations. Their proposed therapeutic regimen includes the use of LAMA or ICS/LABA as first line therapy with combination LABA/LAMA used as second line. Despite the relative paucity of patients in this category, the vast majority are on guidelinerecommended therapy with ICS/LABA, however, most are also on a LAMA, once again suggesting the possibility of over treatment with triple therapy.

Group D: Group D patients are the most severe. They 
have increased symptoms, frequent exacerbations and poor FEV 1 . Combination ICS/LABA or LAMA are first line therapy, with second line therapy including a combination of ICS, LABA, LAMA and PDE4 inhibitors. In our study, therapy in this category was most in keeping with current guidelines.

Although we report a low level of reported use of SABA or SAMA medications in Groups A and B, this may have been affected by the wording of the question, which asked patients to list all the inhalers they used regularly. Patients may therefore have omitted shortacting bronchodilators used as a rescue medication since they did not use these medications regularly. However, the possibility of under prescribing shortacting bronchodilators in GOLD groups $A$ and $B$ cannot be ruled out, which would be a concern given the importance of these agents as a rescue medication in patients with COPD.

Our study population demonstrated a low reliance on PDE-4 inhibitors. Current GOLD guidelines support its use as second line agents in Category $C$ and $D$. Roflumilast, a PDE-4 inhibitor, is known to reduce exacerbations in patients with severe COPD. The role for PDE-4 inhibitors is further strengthened by the recent REACT trial, which demonstrated that roflumilast reduced exacerbations and hospital admissions in patients with severe COPD at risk of frequent and severe exacerbations despite ICS/LABA use or triple therapy use with ICS/LABA/LAMA. ${ }^{20}$ Therefore, particularly in the category $\mathrm{D}$ patients, physicians should consider the addition of a PDE-4 inhibitor even if patients are already on triple inhaled therapy. This is, once again, of the utmost importance in preventing further exacerbations given data demonstrating that after the second severe COPD exacerbation, there is a rapid decline in health status and subsequent exacerbations occur at a much more rapid rate. ${ }^{19}$

Despite being in a tertiary center with expertise in lung disease, the vast majority of COPD patients were not treated in accordance with current guideline recommendations. There was a heavy reliance on ICS/ LABA and triple therapy across all categories. ICS/ LABA combination therapy is covered by provincial health care plans in Ontario for those over age 65 and may account for the overuse of these drugs. In our cohort of patients, of the 267 on triple therapy, 178 or $66.7 \%$ of them were over the age of 65 . Not all provinces or countries have this type of coverage however, overuse of ICS has been a consistent finding reported in studies performed in many developed countries. 5,6

Our study demonstrated an over reliance on ICSs in all categories. While the use of combination ICS/ LABAs has been shown to decrease the risk of COPD exacerbations, ${ }^{21,22}$ use of ICSs has been shown to have side effects, such as an increased risk of pneumonia. ${ }^{23}$

Appropriate use of inhaled corticosteroids is of the utmost importance to obtain maximum benefit without increasing risk unnecessarily. Recent randomized control trials, including the WISDOM and INSTEAD trials have demonstrated that withdrawal of ICSs in selected patients did not increase adverse events. In the WISDOM trial, there was no change in the exacerbation rate during ICS withdrawal or for the year following ICS removal in patients with severe or very severe stable COPD on a long-acting anticholinergic and LABA as maintenance therapy. ${ }^{24}$ In the INSTEAD trial, patients with moderate COPD and low risk of exacerbations were switched from ICS/LABA to indacaterol with no efficacy loss. ${ }^{25}$

In clinical practice, physicians should reassess the need for ICSs in their patients and discontinue it where appropriate to prevent adverse side effects, particularly in treatment categories where ICS is not indicated. Furthermore, The FLAME study, recently published by Wedzicha et al, ${ }^{26}$ demonstrated that patients on a combination LAMA/LABA had an $11 \%$ lower risk of COPD exacerbation then patients treated with an ICS/ LABA combination. This provides further support for limiting the use of ICSs in GOLD category A and B and focusing treatment on maximal bronchodilatation although more research is needed, especially on the role of triple therapy in GOLD group C and D patients.

With the addition in recent years of a wide range of new LAMAs, ultra long-acting LABAs and combination LABA/LAMA inhalers, educating health care providers and updating guidelines with clear and succinct treatment strategies will be important in encouraging a change in inhaler prescription.

Future research should focus on identifying the patients most likely to benefit from ICSs and future guidelines should be as simple and clinically relevant as possible to facilitate uptake by health care providers. One such simplification, which takes into account the relative paucity of patients in GOLD category C, would be replacing the current 4 COPD groups in GOLD with 3 groups arranged in a pyramidal distribution as demonstrated in Figure 7. Groups A and B would have management focused on symptoms with non- 
pharmacologic therapies, including rehab, and optimal bronchodilation. Those in the combined $C+D$ group, which form the top of the pyramid, would focus on both symptom management and prevention of exacerbations potentially including ICSs. Future studies are needed to assess whether a simplified management algorithm impacts COPD outcomes and reduces over prescription of ICSs. Further research is also needed to better identify COPD phenotypes which are more likely to benefit from ICS therapy.

Limitations of this study include the fact that all data was self-reported without confirmation from patient or pharmacy records and data was not obtained on some potentially important therapies such as pulmonary rehabilitation. Reporting bias may have led to underreporting of exacerbations and medication use and an overestimate of adherence. All patients were recruited from a single academic center in Ontario, which limits the generalizability of patient characteristics, and prescribing patterns. However, this pragmatically designed study provides important information regarding guideline discordant therapy in COPD in Ontario and our results are consistent with other studies of therapy in COPD in finding a low incidence of GOLD category $C$ patients and an overreliance on ICSs in all categories of COPD.

\section{Conclusion}

Despite the new GOLD guidelines' categorization of COPD patients and associated treatment algorithm, guideline discordant pharmacotherapy for COPD remains common even in a respiratory specialty clinic and has the potential to increase morbidity and side effects for patients with COPD. More physician education and guideline promotion, not only to primary care physicians but also to those in subspecialty practice, is warranted based on these results.

\section{Declaration of Interest}

A McIvor has received honoraria for attending advisory boards and providing continuing medical education for pharmaceutical companies including: AstraZeneca, Boehringer-Ingelheim, Merck, Novartis, Pfizer, Takeda and Teva. All other authors have nothing to declare. 


\section{References}

1. Mittman N, Kuramato L, Seung SJ, Haddon JM, BradleyKennedy C, Fitzgerald JM. The cost of moderate and severe COPD exacerbations to the Canadian healthcare system. Respir Med. 2008; 102(3): 413-421. doi: https://doi.org/10.1016/j. rmed.2007.10.010

2. Burgel PR, Paillasseur JL, Roche N. Identification of clinical phenotypes using cluster analyses in COPD patients with multiple comorbidities. BioMed Res Int. 2014; 2014: 420134. doi: https://doi.org/10.1155/2014/420134

3. Global Initiative for Chronic Obstructive Lung Disease (GOLD). Global strategy for the diagnosis, management, and prevention of chronic obstructive pulmonary disease: Executive summary 2013. GOLD website. http://www.goldcopd.org Published 2013. Accessed October 2016.

4. Glaab T, Vogelmeier C, Buhl R. Outcome measures in chronic obstructive pulmonary disease (COPD): strength and limitations. Respirology Research. 2010;11:79-90. doi: https://doi.org/10.1186/1465-9921-11-79

5. Price D, West D, Brusselle G, et al. Management of COPD in the UK primary-care setting: an analysis of real-life prescribing patterns. Int J Chronic Obstruct Pulm Dis. 2014; 9(1): 889-917. doi: https://doi.org/10.2147/COPD.S62750

6. Miguel-Díez J, Carrasco-Garrido P, Rejas-Gutierrez J, et al. Inappropriate overuse of inhaled corticosteroids for COPD patients: Impact on health costs and health status. Lung. 2011;189(3): 199-206.

doi: https://doi.org/10.1007/s00408-011-9289-0

7. Laniado-Laborín R, Rendón A, Alcantar-Schramm JM, CazaresAdame R, Bauerle O. Subutilization of COPD guidelines in primary care: A pilot study. J Prim Care Community Health. 2013; 4(3):172-6. doi: https://doi.org/10.1177/2150131913475817

8. Miller MR, Hankinson J, Brusasco V, et al. Standardisation of spirometry. Eur Respir J. 26: 319-338.

doi: https://doi.org/10.1183/09031936.05.00034805

9. Bestall JC, Paul EA, Garrod R, Garnham R, Jones PW, Wedzicha JA. Usefulness of the Medical Research Council (MRC) dyspnoea scale as a measure of disability in patients with chronic obstructive pulmonary disease. Thorax. 1999; 54: 581-6. doi: https://doi.org/10.1136/thx.54.7.581

10. Jones PW, Harding G, Berrry P, Wiklund I, Chen WH, Kline Leidy N. Development and first validation of the COPD Assessment Test. Eur Respir J. 2009;34: 648-654.

doi: https://doi.org/10.1183/09031936.00102509

11. Jones PW, Adamek L, Nadeau G, Banik N. Comparisons of health status scores with MRC grades in COPD: implications for the GOLD 2011 classification. Eur Respir J. 2013;42: 647-654. doi: https://doi.org/10.1183/09031936.00125612
12. Jones PW, Nadeau G, Small M, Adamek L. Characteristics of a COPD population categorised using the GOLD framework by health status and exacerbations. Respir Med. 2014; 108(1):129135. doi: https://doi.org/10.1016/j.rmed.2013.08.015

13. Wesolowskil S, Borosl PW, Debowski T. Chronic obstructive pulmonary disease in Poland: Distribution of patients according to the new GOLD 2011 classification. Cross-sectional survey. Pneumonol Alergol Pol. 2014; 82: 511-517. doi: https://doi.org/10.5603/PiAP.2014.0068

14. Poole P, Chacko EE, Wood-Baker R, Cates CJ. Influenze vaccine for patients with chronic obstructive pulmonary disease (Review). Cochrane Database Syst Rev. 2006; Issue 1: CD002733.

15. Wongsurakiat P, Maranetra KN, Wasi C, Kositanont U, Dejsomritrutai W, Charoenratanakul S. Acute respiratory illness in patients with COPD and the effectiveness of influenza vaccination: a randomized controlled study. Chest. 2004; 125(6): 2011-2020. doi: https://doi.org/10.1378/chest.125.6.2011

16. Scanlon PD, Connett JE, Waller LA, et al. Smoking cessation and lung function in the mild-to-moderate chronic obstructive pulmonary disease. The Lung Health Study. Am J Respir Crit Care Med. 2000; 161 (2 pt 2): 381-392.

doi: https://doi.org/10.1164/ajrccm.161.2.9901044

17. Marciniuk DD, Brooks D, Butcher S, et al. Optimizing pulmonary rehabilitation in chronic obstructive pulmonary disease practical issues: a Canadian Thoracic Society Clinical Practice Guideline. Can Respir J. 2010; 17(4): 159-168. doi: https://doi.org/10.1155/2010/425975

18. Puhan M, Scharplatz M, Troosters T, Walters EH, Sterer J. Pulmonary rehabilitation following exacerbations of chronic obstructive pulmonary disease. Cochrane Database Syst Rev. 2009; 21(1): CD005305.

doi: https://doi.org/10.1002/14651858.cd005305.pub2

19. Suissa S, Dell'Aniello S, Ernst P. Long-term natural history of chronic obstructive pulmonary disease: severe exacerbations and mortality. Thorax. 2012; 67(11): 957-963. doi: https://doi. org/10.1136/thoraxjnl-2011-201518

20. Martinez FJ, Calverley PM, Goehring UM, Brose M, Fabbri LM, Rabe KF. Effect of roflumilast on exacerbations in patients with severe chronic obstructive pulmonary disease uncontrolled by combination therapy (REACT): a multicentre randomized controlled trial. Lancet. 2015; 385(9971): 857-866. doi: https://doi.org/10.1016/S0140-6736(14)62410-7

21. Calverley PM, Anderson JA, Celli B, et al. Salmeterol and fluticasone propionate and survival in chronic obstructive pulmonary disease. $N$ Engl J Med. 200;356(8): 775-789. doi: https://doi.org/10.1056/NEJMoa063070

22. Calverley PM, Boonsawat W, Cseke Z, Zhong N, Peterson S, Olsson H. Maintenance therapy with budesonide and formoterol in chronic obstructive pulmonary disease. Eur Respir J. 2003; 22(6): 912-919.

doi: https://doi.org/10.1183/09031936.03.00027003 
23. Suissa S, Patenaude V, Lapi F, Ernst P. Inhaled corticosteroids in COPD and the risk of serious pneumonia. Thorax. 2013; 68(11): 1029-1036.

doi: https://doi.org/10.1136/thoraxjnl-2012-202872

24. Magnussen H, Disse B, Rodriguez-Roisin R, WISDOM Investigators, et al. Withdrawal of inhaled glucocorticoids and exacerbations of COPD. N Engl J Med. 2014; 371(14): 1285-1294. doi: https://doi.org/10.1056/NEJMoa 1407154

25. Rossi A, van der Molen T, del Olmo R, et al. INSTEAD: a randomized switch trial of indacaterol versus slameterol/ fluticasone in moderate COPD. Eur Respir J. 2014; 44(6): 15481556. doi: https://doi.org/10.1183/09031936.00126814

26. Wedzicha JA, Banerji D, Chapman KR, et al. Indacaterolglycopyrronium versus salmeterol-fluticasone for COPD. $N$ Engl J Med. 2016. 374:2222-2234.

doi: https://doi.org/10.1056/NEJMoa 1516385 